Supporting Information

for

\title{
Enhanced antitumor efficacy and imaging application of photosensitizer-formulated Paclitaxel
}

Linlin Li ${ }^{1}$, Dan Chen ${ }^{1}$, Ke Zheng ${ }^{2}$, Libin Jiang ${ }^{1}$, Tao Dai ${ }^{3}$, Ling Yang ${ }^{1}$, Longguang

Jiang $^{1}$, Zhuo Chen ${ }^{3}$, Cai Yuan ${ }^{4 *}$, Mingdong Huang ${ }^{1 *}$

${ }^{1}$ College of Chemistry, Fuzhou University, Fuzhou, Fujian 350116, China

${ }^{2}$ College of Chemical Engineering, Qingdao University of Science and Technology

${ }^{3}$ State Key Laboratory of Structural Chemistry, Fujian Institute of Research on the

Structure of Matter, Chinese Academy of Sciences, Fuzhou, Fujian, China

${ }^{4}$ College of Biological Science and Engineering, Fuzhou University, Fuzhou, Fujian 350116,

China

Corresponding Author

E-mail: $\underline{\text { HMD lab@,fzu.edu.cn }}$

E-mail: cyuan@fzu.edu.cn 


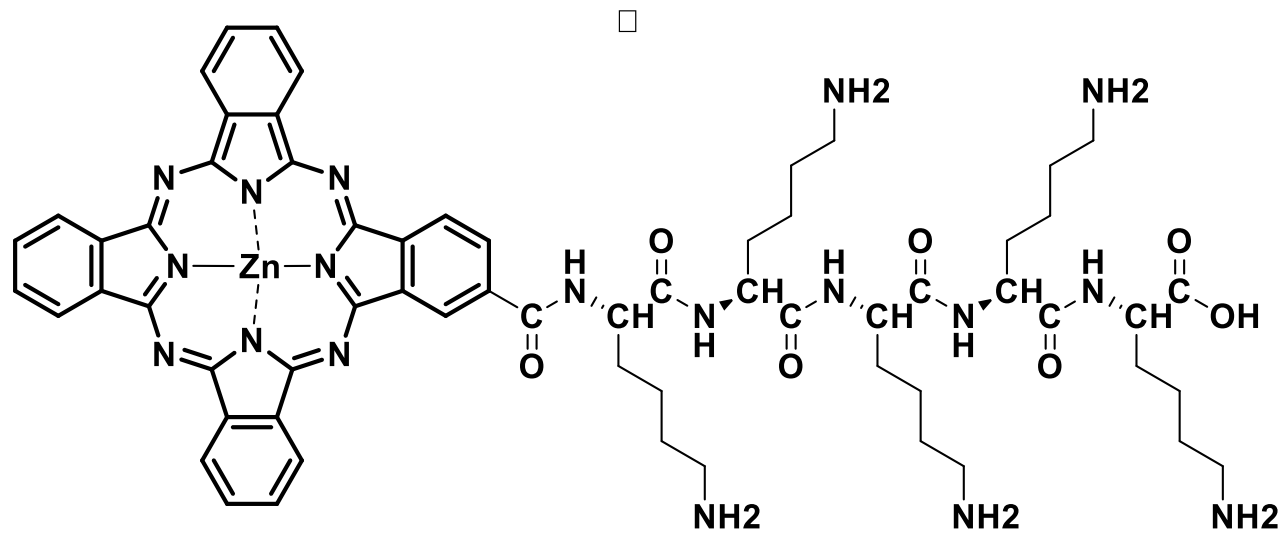

Figure $\mathrm{S} 1$. The chemical structure of $\mathrm{ZnPc}(\mathrm{Lys})_{5}$ 
(A)

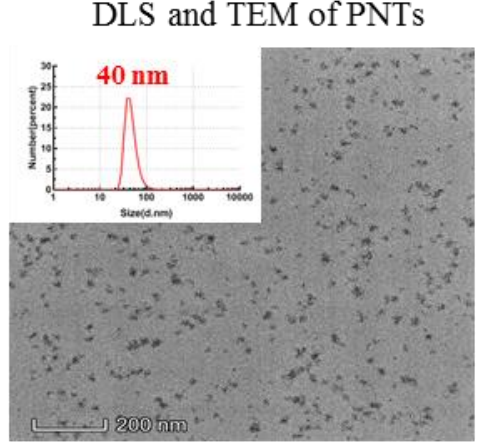

(B)

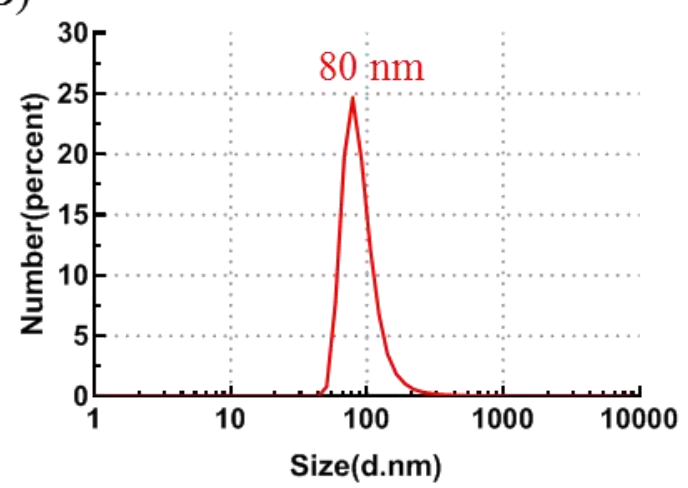

(C)

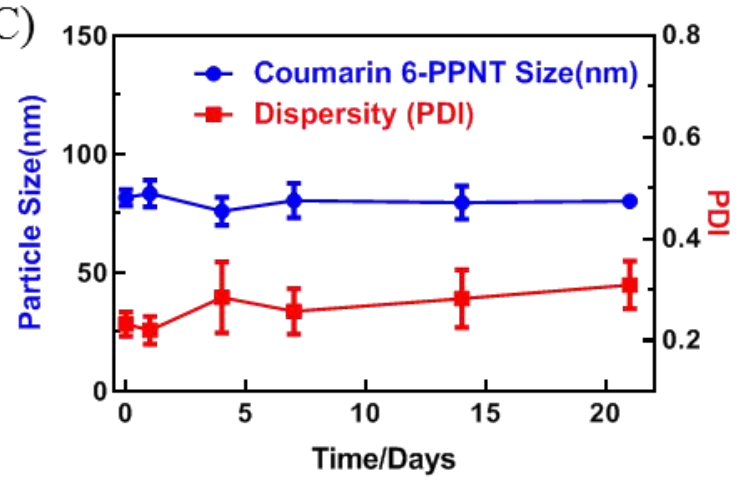

Figure S2. The size distribution of PNTs by TEM and DLS analysis(A). The size of coumarin 6-PPNTs(B) and their stability over 21 days (C).

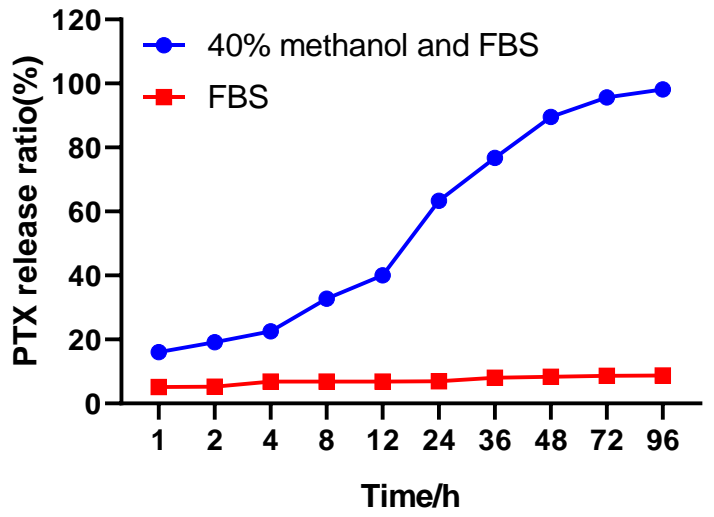


Figure S3. Drug release kinetics of PTX from PPNTs in fetal bovine serum (10\%) in the presence (blue) or absence (red) of $40 \%$ methanol was measured on $\mathrm{C} 18$ column on a HPLC monitoring at $227 \mathrm{~nm}$, showing the high stability of PPNTs. 
(A)
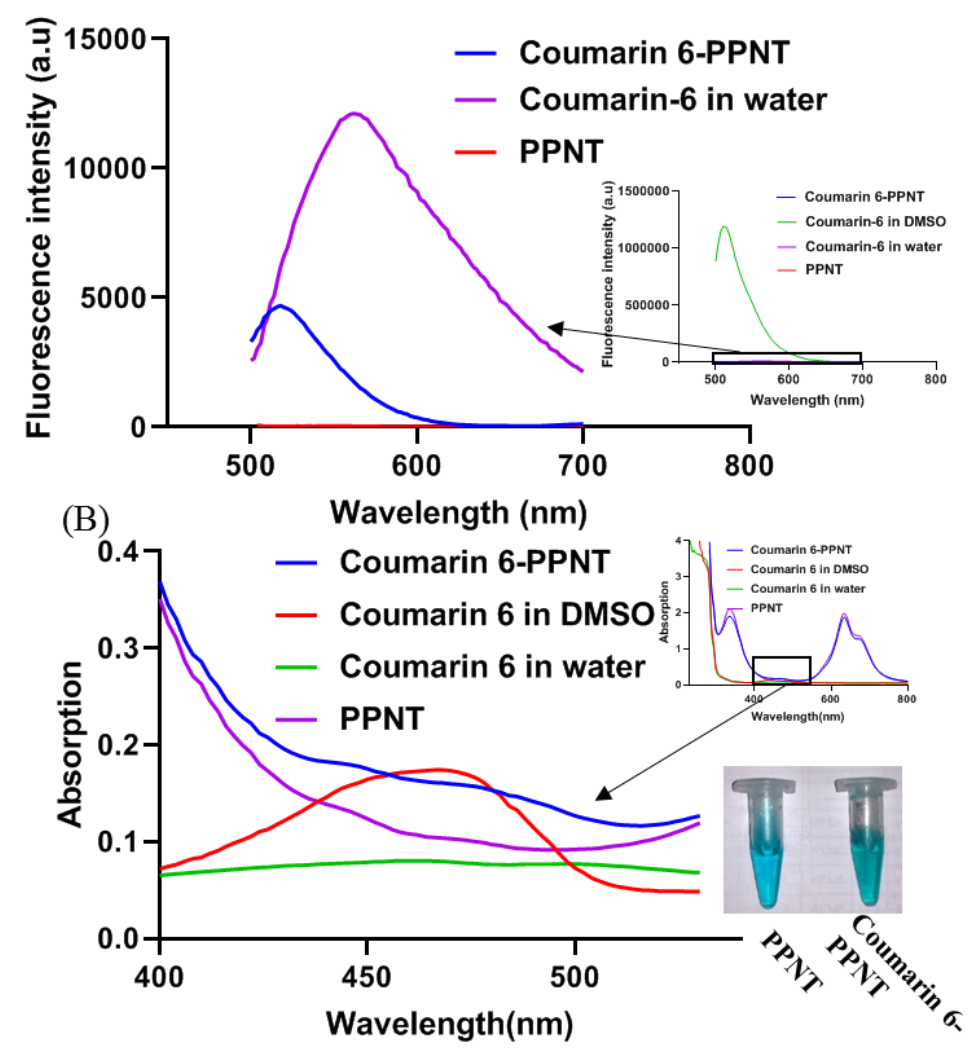

Figure S4. Fluorescence (A) and UV/Vis absorption (B) spectra of the coumarin-6 encapsulated in the PPNTs. 
(A)

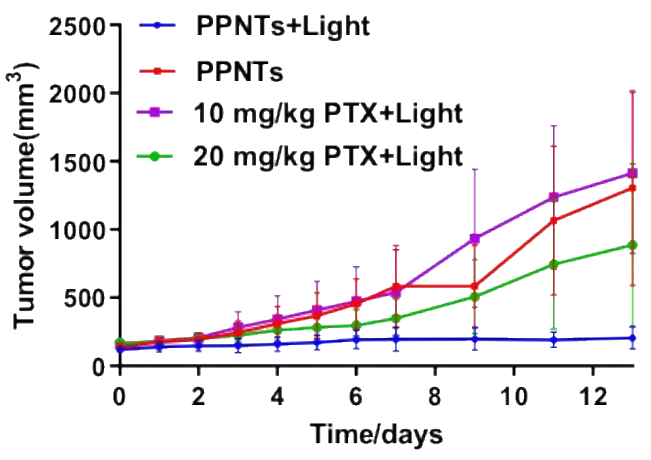

(C)

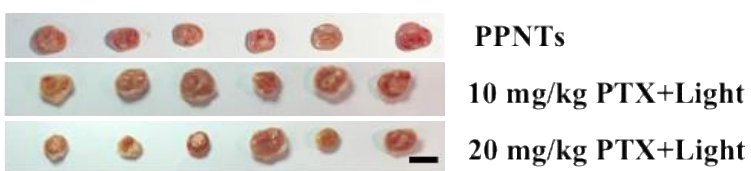

(D)

(E)

$20 \mathrm{mg} / \mathrm{kg}$ PTX+Light
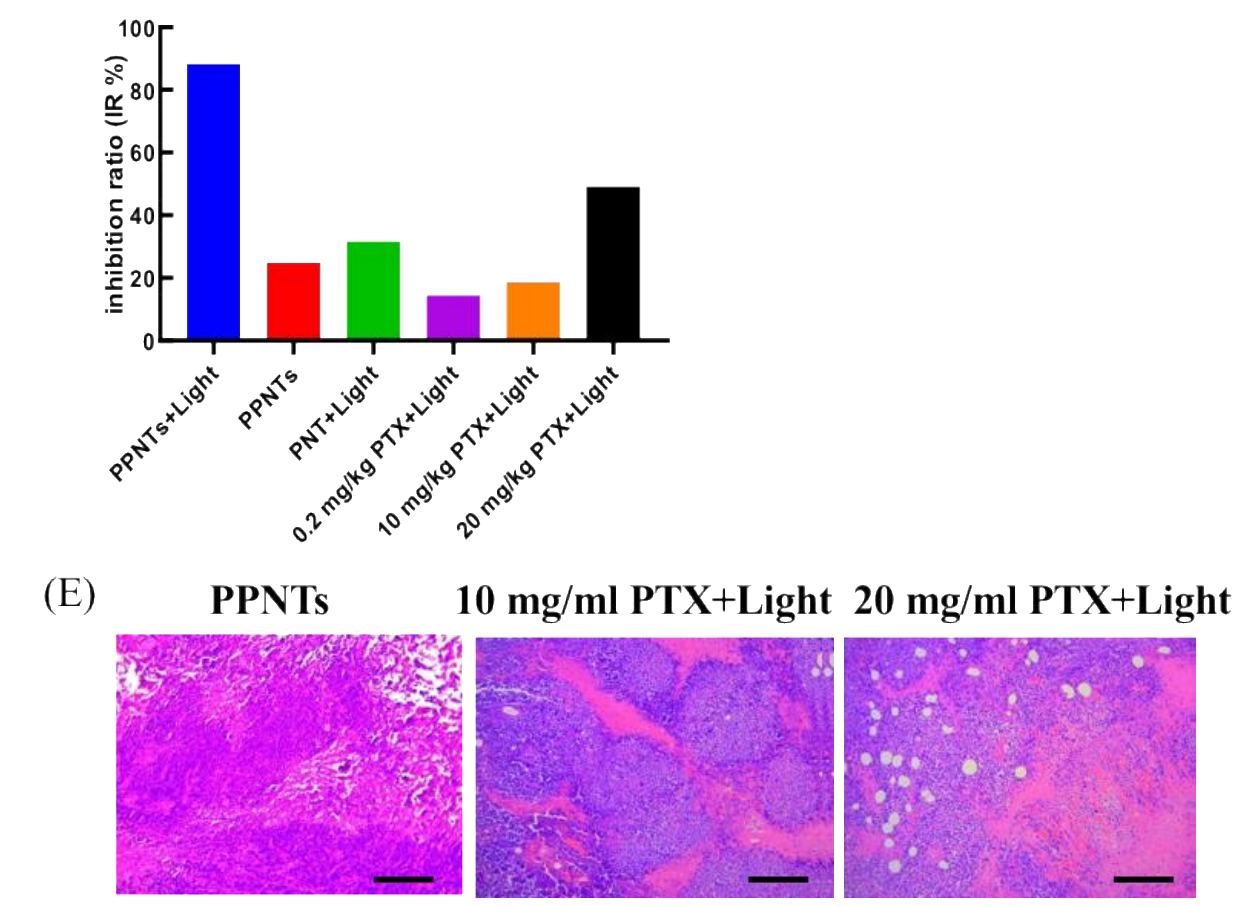

(B)

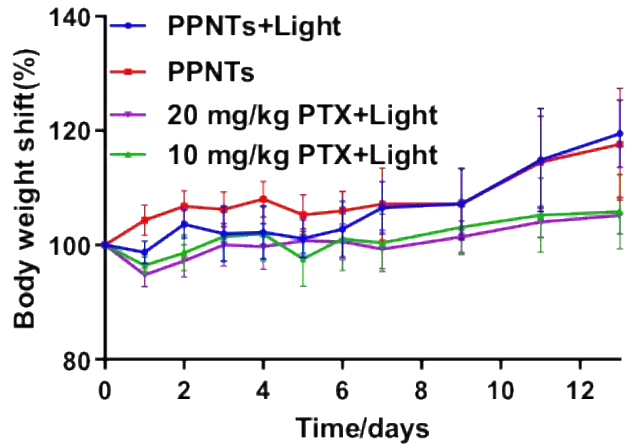

Figure S5. Additional data from the in vivo experiments. (A) Tumor volume on mice upon treatment with PPNTs or other agents as controls in tumor-bearing mice. (B) The mice body weights were recorded as a measure of systemic toxicity. (C) Images of dissected tumors from the PNTs group at the end of treatments (day 14), scale bar represents $15 \mathrm{~mm}$. (D) Its quantification expressed as inhibitory percentages. (E) 
Representative images of $\mathrm{H} \& \mathrm{E}$ staining of tumors from each group dissected at day 14 after treatments.
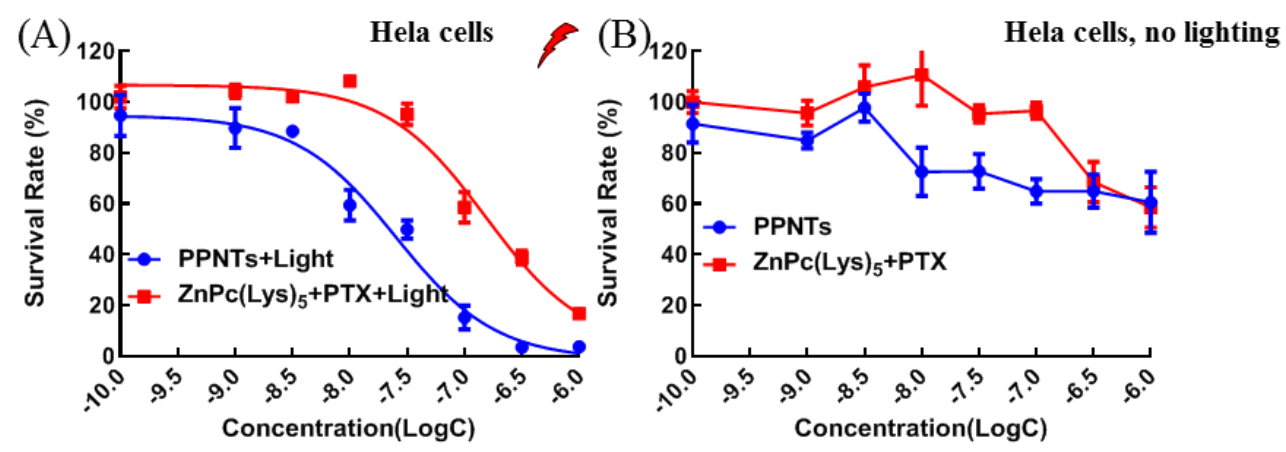

Figure S6. In vitro antitumor efficacy of PPNT (blue dots) and the simple mixture of PTX and PS at the same ratio of PPNT (red squares) in the presence (A) or the absence (B) of light illumination $\left(1.5 \mathrm{~J} / \mathrm{cm}^{2}\right)$ against Hela cells. 


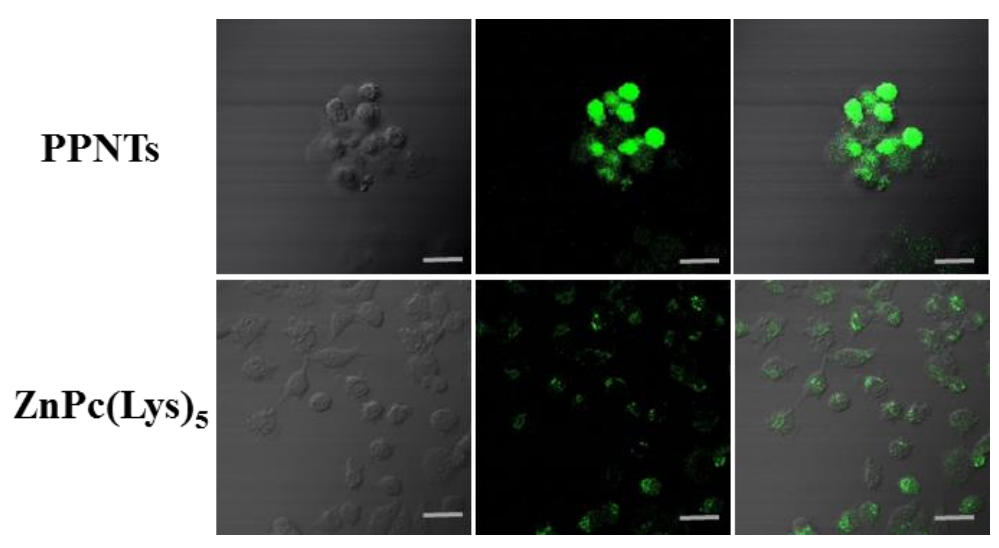

Figure S7. Fluorescence images of intracellular ROS production by PPNTs or $\mathrm{ZnPc}(\mathrm{Lys})_{5}$ in Hela cells as determined by DCFH-DA probe. The green fluorescence indicated ROS production after PDT treatment. Scale bar represents $30 \mathrm{~mm}$. 

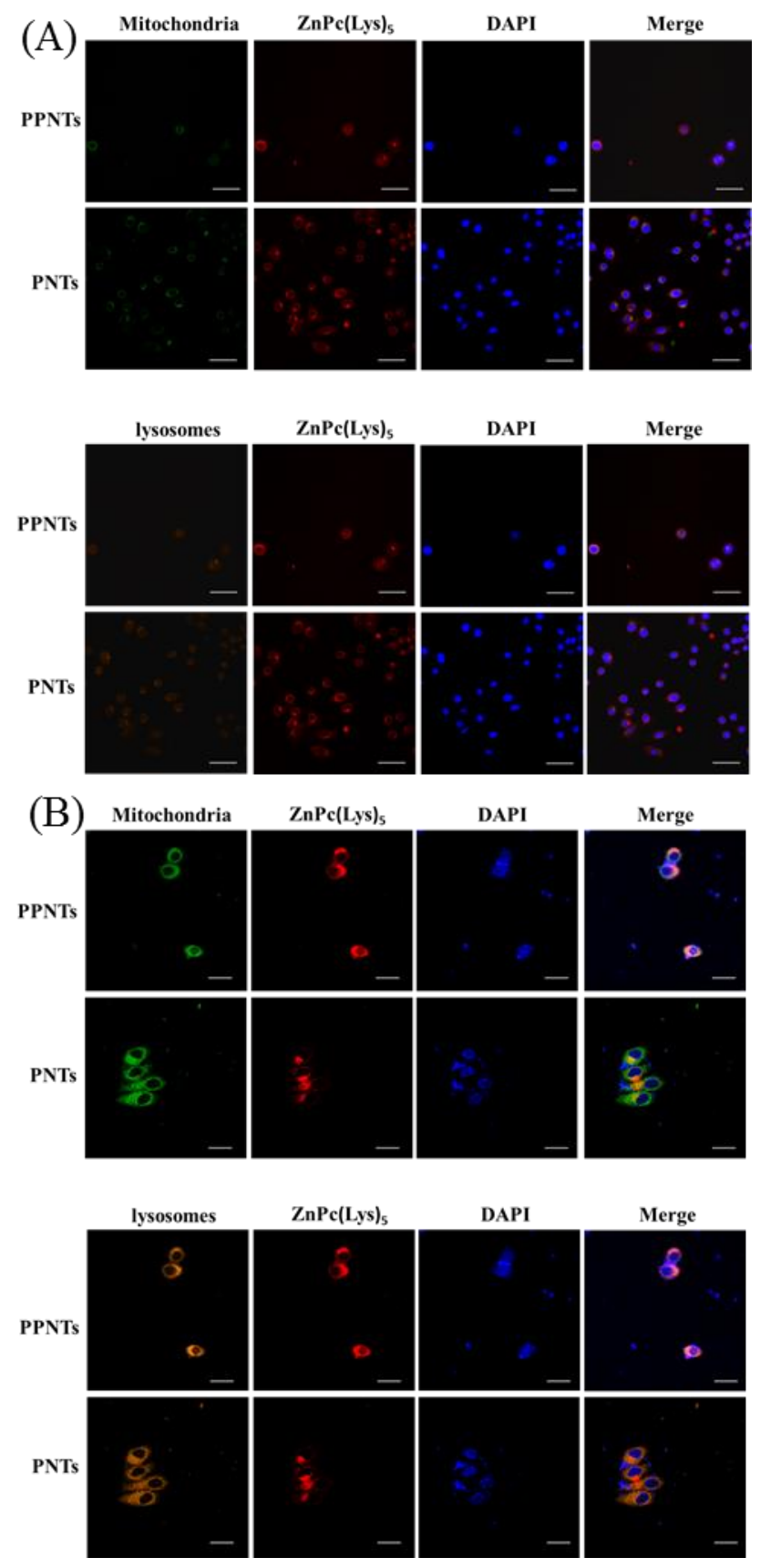

Figure S8. Intracellular co-localization of PPNTs or PNTs with mitochondria and with lysosome in Hela cells(A) or EC109 cells(B). Scale bar represents $30 \mathrm{~mm}$ 
PTX

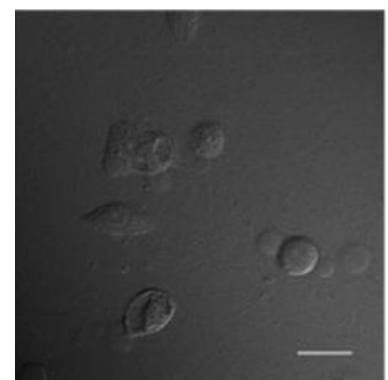

PPNTs

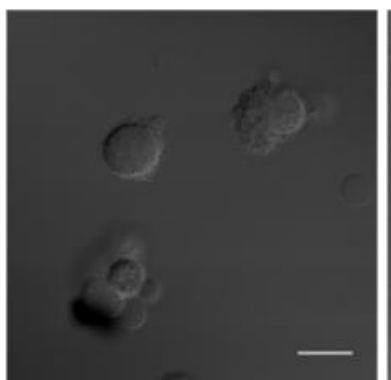

PNTs

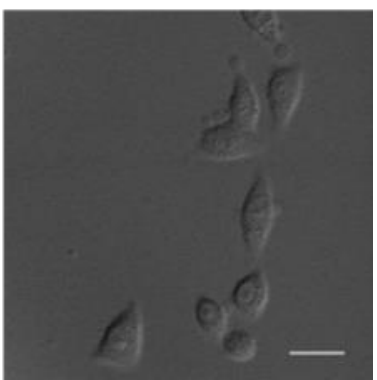

Figure S9. Morphology of EC109 cells treated by PTX, PNTs, or PPNTs at $100 \mathrm{nM}$ for $24 \mathrm{~h}$. Scale bar represents $30 \mu \mathrm{m}$.

\begin{tabular}{ccccc}
\hline $\begin{array}{c}\text { Zeta } \\
\text { potential }\end{array}$ & PPNTs & PNTs & $\begin{array}{c}\text { Coumarin 6- } \\
\text { PPNTs }\end{array}$ & ZnPc(Lys) \\
\hline & 22.0 & 21.0 & 23.0 & 23.3 \\
\hline
\end{tabular}

Table S1. Zeta potential of the nanoparticles and $\mathrm{ZnPc}(\mathrm{Lys}) 5$, measured at equivalent molar concentrations. 


\begin{tabular}{cccc}
\hline Ingredient & $\begin{array}{c}\text { Initial } \\
\text { concentration }\end{array}$ & $\begin{array}{c}\text { Assembled } \\
\text { concentration }\end{array}$ & $\begin{array}{c}\text { Encapsulation } \\
\text { Efficiency (\%) }\end{array}$ \\
\hline PTX & $85.4 \mu \mathrm{g} / \mathrm{ml}$ & $79.4 \mu \mathrm{g} / \mathrm{ml}$ & $93.3 \%$ \\
\hline $\mathrm{ZnPc}(\mathrm{Lys})_{5}$ & $123.6 \mu \mathrm{g} / \mathrm{ml}$ & $115.4 \mu \mathrm{g} / \mathrm{ml}$ & $93.3 \%$ \\
\hline
\end{tabular}

Table S2. The encapsulation efficiency (EE\%) for the assembly of PPNTs, which was calculated as follows: $\mathrm{EE} \%=\left(\mathrm{PTX}\right.$ or $\mathrm{ZnPc}(\mathrm{Lys})_{5}$ entrapped in the NPs/ PTX or $\mathrm{ZnPc}(\text { Lys })_{5}$ initially added $) \times 100 \%$. 